\title{
Breeding failure of seabirds in relation to fish depletion: Is there one universal threshold of food abundance?
}

\author{
Magella Guillemette ${ }^{1}$, François Grégoire ${ }^{2}$, Dévrig Bouillet ${ }^{1}$, Jean-François Rail ${ }^{3}$, \\ François Bolduc $^{3}$, Alain Caron ${ }^{1}$, David Pelletier ${ }^{1,4, *}$ \\ ${ }^{1}$ Département de biologie et géographie, Université du Québec à Rimouski, Rimouski, QC G5L 3A1, Canada \\ ${ }^{2}$ Fisheries and Oceans Canada, Mont-Joli, QC G5H 3Z4, Canada \\ ${ }^{3}$ Environment and Climate Change Canada, Canadian Wildlife Service, Québec, QC G1J 0C3, Canada \\ ${ }^{4}$ Cégep de Rimouski, Rimouski, QC G5L 4H6, Canada
}

\begin{abstract}
Many populations of seabirds are in decline across the world and one proposed cause is the global collapse of fish stocks. Recently, it has been shown that breeding success starts to decline at some critical threshold (CT) of maximum prey abundance (MPA). Here, we estimated this empirical threshold for a large seabird, the northern gannet Morus bassanus, and discuss its relevance under various conditions. Using a time series starting at the end of the 1970s that included estimated biomass of fish, gannet population and food consumed by gannets, we found a positive and non-linear relationship between fish biomass and breeding success. This correlation was supported by the results of a bio-energetic model indicating that gannets extract a substantial fraction of the available biomass. In addition, distribution and time spent at sea (derived from GPS recordings) increased considerably when food abundance was low. In contrast to the general CT previously proposed (34\%), we found that breeding success of gannets started to decline at about $8 \%$ of MPA. Moreover, when corrected for the sizes of prey available that may be eaten by the birds and the removal of fish by the fishing industry, the observed threshold was further reduced, indicating that such effects should be included in the context of ecosystem based management. Theoretical considerations are offered to further explain the discrepancy between the results of our study and a previously published meta-analysis, which included the effect of diet on feeding profitability and the effect of population size.
\end{abstract}

KEY WORDS: Bird consumption - Breeding success - Conservation threshold · Fishing impact · Numerical responses · Prey profitability

\section{INTRODUCTION}

Functional and numerical responses are cornerstones of system ecology. While the functional response expresses the efficiency of a predator to extract energy from its environment in relation to prey abundance, the numerical response reports the ability of predators to transform food biomass into population growth. In a seminal paper, Cairns (1987) proposed that various biological parameters of a

${ }^{*}$ Corresponding author:

david.pelletier@cegep-rimouski.qc.ca given seabird species would vary in a non-linear fashion in relation to food abundance, similar to a functional response. Here, the functional link to breeding success is foraging profitability, where a high energy return will be associated with a high reproductive success. Recently, Cury et al. (2011) demonstrated how various populations of seabirds react to fish depletion: breeding success increases positively with prey abundance and then levels off when prey are abundant. These authors also showed

(C) M. Guillemette, D. Bouillet, A. Caron, D. Pelletier, The Crown in the Right of Canada 2018. Open Access under Creative Commons by Attribution Licence. Use, distribution and reproduction are unrestricted. Authors and original publication must be credited.

Publisher: Inter-Research · www.int-res.com 
that breeding success starts to decline at one-third of maximum prey abundance (MPA), when averaged over various species of seabirds across the world.

Although such a critical threshold (CT) might be of great value for conservation purposes and ecosystem based management (Hunsicker et al. 2011, Shelton et al. 2014), Cury et al. (2011) did not consider the possibility that only a part of prey biomass is available to bird predators. For instance, there must be some maximum fish size that can be swallowed by a bird, or alternatively, only the fish present in the upper part of the water column might be available given the diving capacity of each bird species. In addition, the impact of fisheries was not integrated in the modelling exercise, and in some cases, fisheries compete with birds (Pichegru et al. 2010, Danckwerts et al. 2014, Peck et al. 2014). On theoretical grounds, such a CT will also depend on whether a fish species supporting the bird population is a preferred prey or not (see 'Discussion'). Otherwise, a decline in fish prey may have little or no influence on the breeding population of seabirds. Therefore, all these factors may strongly influence the computation of a CT of food abundance.

Using data covering a period of $40 \mathrm{yr}$, we tested the threshold value proposed by Cury et al. (2011) for a large population of northern gannets Morus bassanus breeding in the Gulf of St. Lawrence (GSL), eastern Canada, where the Atlantic mackerel Scomber scombrus L. is the preferred prey. Gannets are large (3 kg), plunge-diving birds, catching pelagic fishes down to $10 \mathrm{~m}$ (Garthe et al. 2014). They reach fishing areas by flying up to 100 s of $\mathrm{km}$ away from their colonies during trips lasting several hours or even days (Garthe et al. 2007, Hamer et al. 2007) in order to feed their single chick. Using independent data on food biomass and fishing landings of mackerel, we tested whether there is one universal threshold of food biomass below which breeding success decreases by relating reproductive success to (1) food biomass and (2) biomass available to gannets, by subtracting the prey too large to be eaten and the amount of mackerel removed by the fishing industry, together with some theoretical considerations.

\section{MATERIALS AND METHODS}

\section{Study area and monitoring programs of birds and fish}

The GSL is one of the largest bodies $\left(226000 \mathrm{~km}^{2}\right)$ of internal water within the Canadian marine envi- ronment. The southern part of the Gulf is considered the main spawning area of Atlantic mackerel in Canadian waters (Sette 1943). In this area, the feasibility of a population survey based on egg sampling was demonstrated in the late 1970s (see Grégoire \& Faucher 2006 for a review). Following this result, the survey has been conducted annually or biennially since 1983 (Grégoire et al. 2014). The spawning stock biomass (SSB) of mackerel is estimated from the survey according to the total egg production method (TEPM) (Saville 1977). Our method assumes that the southern GSL is the main mackerel spawning area in Canadian waters. This was investigated in 2009 with egg surveys that were also conducted in surrounding areas, namely the Scotian Shelf and the south and west coasts of Newfoundland (Grégoire et al. 2013a,b). The contribution of these areas to the stock was small, and confirmed, at least for 2009, that the southern GSL is by far the most important spawning area of mackerel in the region (Grégoire et al. 2014). Canadian landings data were obtained from the Canadian Department of Fisheries and Oceans. Following each fishing season, these data are compiled from fishing logbooks and purchase slips and are grouped by province, Northwest Atlantic Fisheries Organization (NAFO) division, sub-division and unit area as well as by month and type of fishing gear. The fishing season starts in mid-May and lasts until November and thus overlaps with the gannets' reproductive season. Fishers operate from different ports all around the GSL, thereby reducing the probability of fisher concentration.

The gannet population inhabiting the GSL is composed of 3 colonies (Bird Rock: $47.83^{\circ} \mathrm{N}, 61.15^{\circ} \mathrm{W}$; Bonaventure Island: $48.50^{\circ} \mathrm{N}, 64.15^{\circ} \mathrm{W}$; Anticosti Island: $49.15^{\circ} \mathrm{N}, 61.70^{\circ} \mathrm{W}$ ) that are regularly monitored with the methods described by Rail et al. (2013). Briefly, at each colony the number of breeding pairs is monitored through aerial photographs. High-quality film or digital images of each colony are taken through an open window of fixed-wing aircraft (Britten-Norman Islander or Partenaria aircraft). Colonies are overflown usually between 7 and 12 July. The population size for 2005 and 2008 was estimated by interpolation using the population growth rate estimated by Rail et al. (2013). This timing corresponds with a period of the breeding season when most birds are attending a nest containing a chick or, rarely, an egg, but before nests of failed breeders would be abandoned and so degraded that they are no longer visible on the photographs. For Atlantic mackerel, this also corresponds to the time of maximum egg production (Grégoire et al. 2014). 


\section{Diet and productivity}

Gannets tend to regurgitate spontaneously when gently disturbed (e.g. by persons walking slowly alongside the colony) during the breeding season. Every week, collections of regurgitations were made, brought about either by investigators walking along the edge of the colony or when gannets were captured for weighing or GPS deployment. Given that all regurgitated prey were fish, we do not believe that there was any digestion bias in our method. From the end of May to the end of September, collecting sessions were made with the objective of collecting approximately 10 regurgitations per week. The mass of each regurgitation was recorded together with the mass of each fish species taken separately. Diet varies seasonally during the reproduction period of gannets; mackerel start to appear during the second week of June, coinciding with the median of egg hatching of this population. As such, mackerel is the most important prey during the chick-rearing period. For these reasons, the relative importance of mackerel was taken only for years where a complete and systematic seasonal coverage was obtained (midJune to mid-September, $\mathrm{n}=6 \mathrm{yr}$ ).

Fledging productivity at the Bonaventure colony has been monitored since 1969, but we only considered data from 1979 to match the database of mackerel SSB. The monitoring of this colony has been described elsewhere (Rail et al. 2013). Briefly, the contents of each nest defended by a gannet pair is determined from 4 to 8 plots distributed over the colony, which includes between 180 and 600 nests per year. Monitoring starts during the incubation period; the position of each nest is numbered on a photograph, then the nest content is determined by visual observation. Later in the season (usually at the beginning of September), the number of chicks present in each numbered nest is recorded. From these data, we estimated the fledging productivity of the colony calculated as the number of chicks produced divided by the number of nests with eggs.

\section{Modelling prey consumption}

The amount of mackerel consumed by the GSL gannet population was estimated using a bio-energetic model, where adult daily energy expenditure (DEE), digestibility and caloric content of prey, respectively, were set at $4865 \mathrm{~kJ} \mathrm{~d}^{-1}$ (Birt-Friesen et al. 1989), $75 \%$ (Cooper 1978) and $7.5 \mathrm{~kJ} \mathrm{~g}^{-1}$ (Spitz \& Jouma 2013). We used $54 \%$ as the relative importance of mackerel in the gannet diet based on 5 reproductive seasons (2004 to 2014, $\mathrm{n}=709$ ). Because mackerel importance was high for a 6 th year $(1974 ; 91 \%)$, we also estimated the amount of mackerel eaten by this population with a diet consisting of $100 \%$ mackerel (see 'Results'). Given that we observed that mackerel are included in the diet of gannets from the median hatching date (26 June) to the end of September, we used $100 \mathrm{~d}$ as the window of time for our calculations of mackerel consumption in any given year. Thus, one adult gannet would consume $438 \mathrm{~g}$ of mackerel for each of the $100 \mathrm{~d}$ when its relative importance in the diet represents $54 \%$, or $811 \mathrm{~g}$ when its importance is $100 \%$. The amount of fish consumed during $100 \mathrm{~d}$ was multiplied by the total number of reproductive individuals present in the GSL for any given year to obtain yearly population mackerel consumption.

We added to this estimate consumption of mackerel by non-breeding individuals and consumption by chicks, assuming a similar importance in their diet $(54 \%)$ as for reproductive adults. The number of nonbreeding individuals was derived from yearly estimates of non-breeding birds at the colony, which is $11.3 \%$ on average $(\mathrm{n}=8 \mathrm{yr})$. We did not consider consumption of fish by immature birds not present at the colony in our total estimate, because this part of the population is not surveyed and is of unknown size. Chicks' consumption of fish until fledging was obtained from Montevecchi et al. (1984), who estimated it to be $24.2 \mathrm{~kg}$ on average from 2 captive individuals with similar growth curves as wild individuals, giving a total seasonal amount of $13.06 \mathrm{~kg}(24.2 \times 0.54)$ of mackerel consumed by 1 chick over 1 season. This amount was multiplied by the total number of chicks produced each year at the Bonaventure colony, estimated from breeding productivity, ranging from $2.7 \%$ to $77 \%$ between 1976 and $2014(\mathrm{n}=14)$. Finally, we used a similar approach for the 2 other colonies located at Anticosti Island and Bird Rock. Because productivity and diet were not monitored at these latter colonies, we assumed that the parameter estimates were similar to that of the Bonaventure colony.

\section{GPS tracking}

We deployed 108 GPS loggers on gannets breeding at Bonaventure Island, Québec in July and August 2012, 2013 and 2014. Gannets were tracked from their breeding colony using iGotU GT-120 GPS data loggers (Mobile Action Technology; dimensions: 44.5 $\times 28.5 \times 13 \mathrm{~mm}$ ) during the chick-rearing period. All loggers were attached to the tail below the uropygial 
gland with waterproof tape (Tesa 4650; Wilson et al. 1997). This technique does not damage the birds' feathers. The GPS devices were sealed and the air removed with a vacuum machine. The loggers including the sealing plastic weighed $35 \mathrm{~g}$ on average $(1.2 \%$ of mean gannet body mass). GPS coordinates were recorded every $10 \mathrm{~min}$. We caught birds on their return to the colony after $10 \mathrm{~d}$ on average as they arrived from a foraging trip, and the devices were removed and the data downloaded. To compare the foraging distribution of Bonaventure's gannets during a year of high food abundance $(2003$; data from Garthe et al. 2007) with years of low abundance (2012 to 2014), we used only a subset of our data set covering a similar seasonal period (August, $\mathrm{n}=63$ individuals, 73 foraging trips).

\section{Data analysis}

The relationship between gannet breeding success and mackerel abundance was investigated using the package 'segmented', version 0.5-1.4 (Muggeo 2008) run with the R software, version 3.2.3 (R Core Team 2015). The segmented package estimates linear and generalized linear models having one or more segmented relationship in the linear predictor. Slope and breakpoint are estimated using an iterative procedure (Muggeo 2003) that requires starting values for the breakpoint parameter. The package also includes a bootstrap restarting method that renders the algorithm less sensitive to starting values (Wood 2001).
For comparison purposes, we also ran the analysis with the method given by Cury et al. (2011, their supplementary material) to find that the 2 methods gave different results (see Table 1 and 'Discussion'). Another point of contention relates to the fact that using a relative $\mathrm{CT}$ based on a single (and often extreme) value of food abundance (as used by Cury et al. 2011) is not sufficiently robust. Thus, we expressed the relative threshold or breakpoint in relation to the 5 most important years in terms of food biomass of mackerel (see Table 1)

\section{RESULTS}

\section{Diet of gannets}

The diet of gannets varied during their reproductive period and included mackerel, capelin Mallotus villosus, herring Clupea harengus and sand eels Ammodytes spp. (Fig. 1). However, mackerel were the predominant prey over most of the chick-rearing period, which usually ends by the end of September (Poulin 1968). When compared through years, the relative importance (wet mass) of mackerel in the gannets' diet showed a negative trend through time $\left(\mathrm{r}=-0.862, \mathrm{n}_{\text {years }}=6, \mathrm{n}_{\text {regurgitations }}=838, \mathrm{p}<0.05\right)$, and ranged from $91 \%$ in 1974 to $38 \%$ in 2013. However, this relationship was no longer significant $(p>0.05)$ when data from 1974 were removed, and mackerel averaged $54 \%$ in relative importance for the remaining 5 yr (Fig. 1).
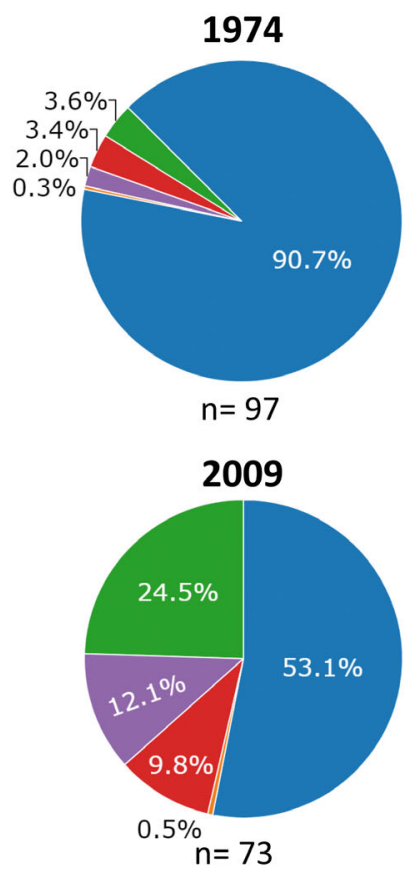

2004

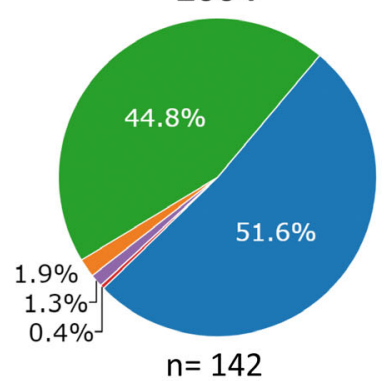

2013

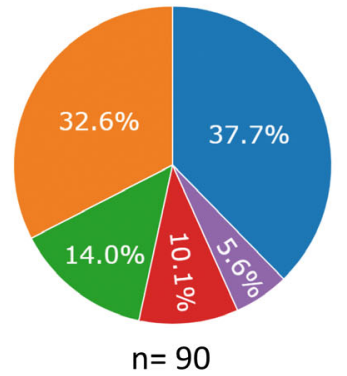

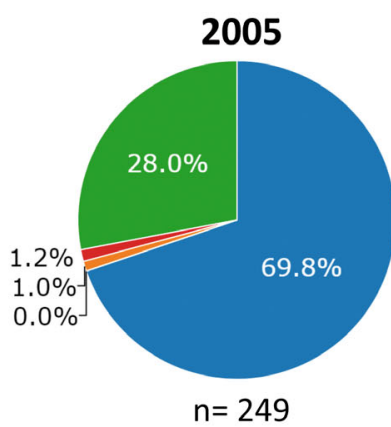

2014

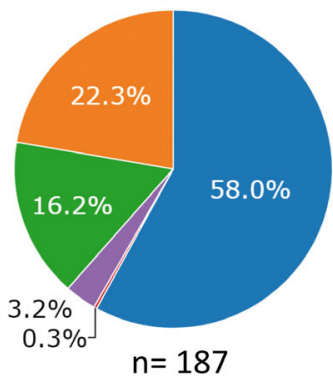

Atlantic Mackerel (Scomber scombrus) - Sand Eel (Ammodytes sp.) Atlantic Herring (Clupea harengus) - Capelin (Mallotus villotus) Others

Fig. 1. Annual variation in the diet of northern gannets from Bonaventure Island colony (1974 to 2014) illustrated as the relative importance ( $\%$ mass) of fish prey ( $\mathrm{n}=$ sample size). When 1974 is excluded, the relative importance of Atlantic mackerel is $54 \%$ on average for the 5 remaining years. Data for 1974 are from Taylor \& Nettleship (1974) and data for 2004, 2005 and 2009 are from Rail et al. (2013) 


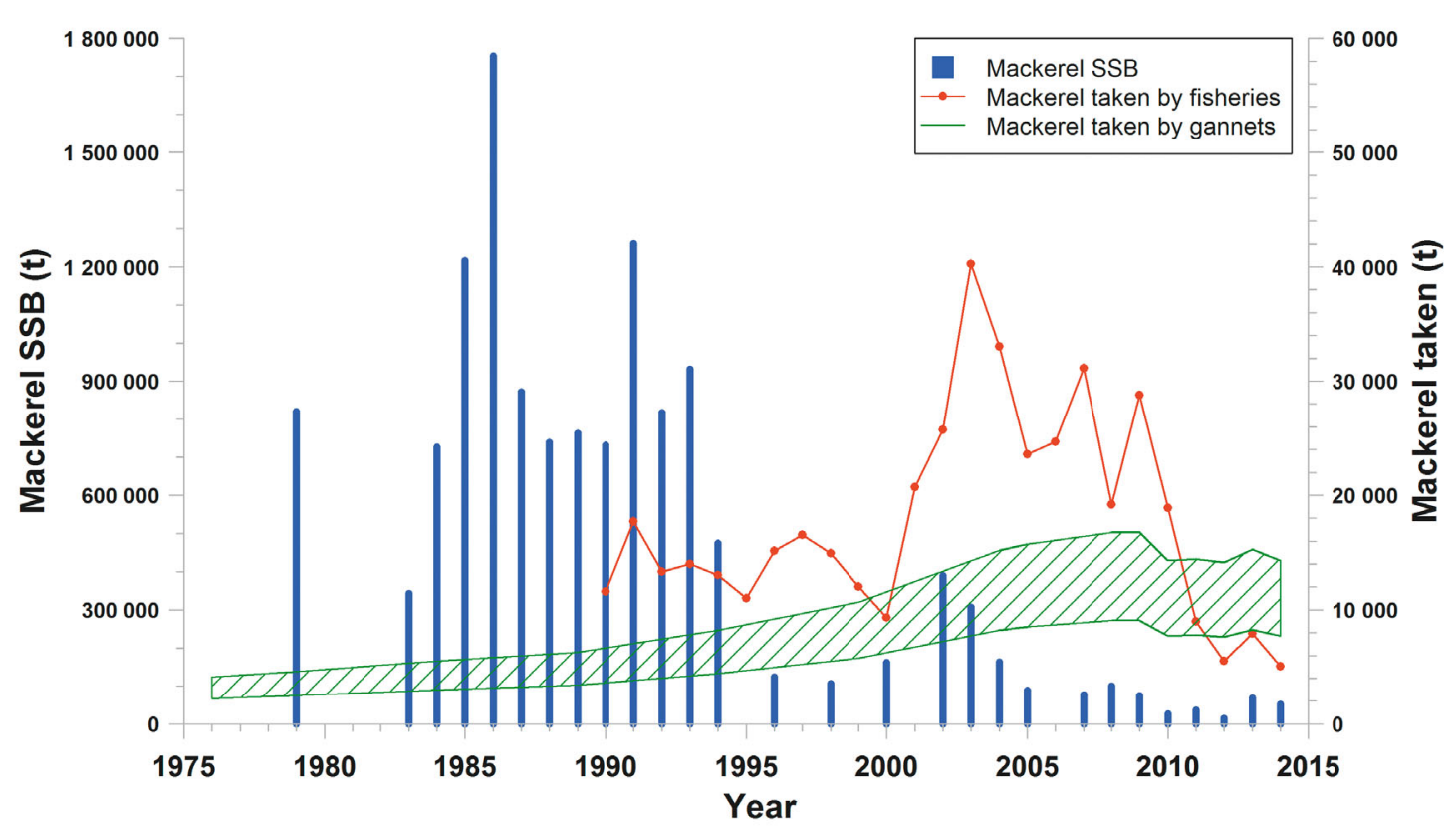

Fig. 2. Atlantic mackerel spawning stock biomass (SSB; in metric tonnes, t) in the Gulf of St. Lawrence (GSL) in relation to time, together with the amount of fish landings (red line) and the amount of mackerel consumed by gannets (green line, see 'Materials and methods'). Note that vertical axes are on different scales; the upper part of the gannets' consumption curve assumes $100 \%$ mackerel relative importance in diet and the lower part, $54 \%$

\section{Biomass of mackerel relative to gannets' productivity}

The available mackerel biomass varied by 2 orders of magnitude in the GSL over the study period, from about 1500000 metric tonnes (t) in the mid-1980s to only 15000 t in 2012 (Fig. 2). Fish landings increased from $10000 \mathrm{t}$ in 1990 to a peak of $40000 \mathrm{t}$ in 2003, representing about $13 \%$ of the available biomass (307 000 t) in 2003. During the same period (2003), the consumption of mackerel by the gannet population represented $8200 \mathrm{t}$, or about $5.0 \%$ of SSB (Fig. 2). However, the relative amount of mackerel taken increased markedly afterwards, with a further decrease of SSB with peaks of $53 \%$ by the gannet population in 2012 (see 'Discussion').

From 1979 to 2005, the productivity of northern gannets at Bonaventure Island averaged $( \pm \mathrm{SD}) 73.0$ $\pm 3.0 \%(\mathrm{n}=6)$, and dropped to $31.2 \pm 18.2 \%(\mathrm{n}=7)$ between 2008 and 2014. The productivity of gannets was at first linearly related to mackerel biomass and then levelled off at about $72 \%$ (Fig. 3a). We obtained a similar relationship when considering only mackerel of suitable size for gannets $(<35 \mathrm{~cm})$. Using segmented regressions, we determined that the threshold of uncorrected mackerel biomass at which breeding success started to decrease was $132300 \mathrm{t}$ $(\mathrm{CI}=45160-219400 \mathrm{t})$, and $97370 \mathrm{t}(\mathrm{CI}=28700-$
$166000 \mathrm{t})$ for biomass corrected for size of fish (Table 1). Moreover, when subtracting both the amount of fish landings and fish too large to be swallowed by gannets, we obtained an even lower threshold of $78840 \mathrm{t}(\mathrm{CI}=49090-108600 \mathrm{t})$.

The impact of a low biomass of fish on the gannets' foraging strategy was illustrated by comparing their foraging range during 2003 (a productive year with $307000 \mathrm{t}$ of mackerel biomass) with that of 2012 to 2014 (14568-68547 t). Clearly, gannets expanded their range substantially in their search for food, being now observed in various areas in which they were not previously found in the GSL (Fig. 4a). In addition, the time spent at sea increased considerably ( $t=2.30, \mathrm{p}<0.05$ ), from about $28 \mathrm{~h}$ on average in 2003 ( $\mathrm{n}=14$ individuals, $\mathrm{n}=20$ foraging trips) to $44 \mathrm{~h}$ in 2012 to 2014 ( $\mathrm{n}=63, \mathrm{n}=73$; Fig. 4b).

\section{DISCUSSION}

Seabird breeding success is often highly variable among years, and may reflect variations in food abundance (Frederiksen et al. 2007, Piatt et al. 2007, Bertrand et al. 2012, Velarde et al. 2013, Robinson et al. 2015, and references therein). It is thus not surprising that $30 \mathrm{yr}$ ago it was proposed that seabirds be used as indicators of marine food supplies (Cairns 

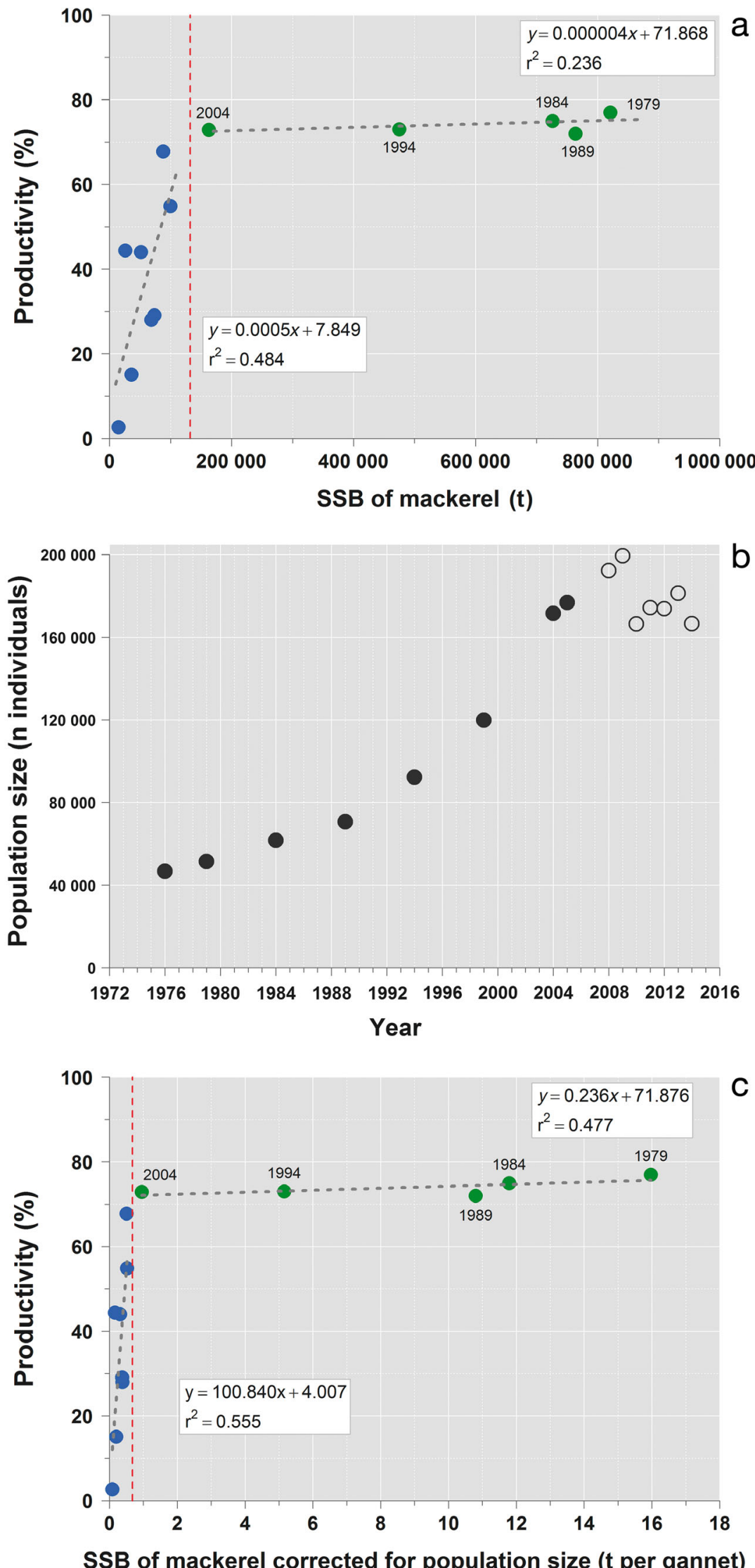

1987). Recently, it has been further suggested that the relationship between food abundance and bird breeding success be used as a 'signal' to conservation efforts of both prey and predator populations. Here, we present such data spanning 4 decades. More specifically, we tested the idea that decreases in seabird productivity begin to appear at about one-third of food biomass, using various metrics of food abundance together with theoretical considerations. To further substantiate our interpretation, we present results stemming from a bio-energetic model along with GPS recordings in order to unravel the mechanisms by which food depletion may influence breeding success.

\section{Empirical considerations}

Various populations of seabirds are in decline across the world (Paleczny et al. 2015), and one possible cause is the global collapse of fish stocks (Pichegru et al. 2010, Bertrand et al. 2012, Robinson et al. 2015). If one-third of MPA is to be used as a general CT for predatorprey populations and a relevant conservation ratio, we need to know the nature and extent of fish harvest in the ecosystem investigated. Cury et al. (2011) gave no indication of the extent to which the various time series of forage fish popula-

Fig. 3. (a) Productivity (\% fledging success) of northern gannets breeding on Bonaventure Island in relation to spawning stock biomass (SSB) of mackerel between 1979 and 2004. Segmented regression analysis indicates that breeding success started to decline at 132000 t of mackerel SSB (vertical dash line). (b) Evolution of the Gulf of St. Lawrence (GSL) gannets' population size (no. of reproductive individuals). Open symbols are associated with an average breeding success of $31.2 \%(\mathrm{CV}=$ $58.3 \%)$; filled symbols: $72.6 \%(\mathrm{CV}=4.1 \%)$. (c) Productivity (\% fledging success) of northern gannets breeding on Bonaventure Island in relation to SSB of mackerel per capita (corrected for population size of gannets). Segmented regression analysis indicates that breeding success started to decline at $0.75 \mathrm{t}$ of mackerel SSB ind. ${ }^{-1}$ 
Table 1. Estimated thresholds of biomass (metric tonnes, t) at which breeding success of northern gannets starts to decrease, using the method of Cury et al. (2011) and segmented regressions. Uncorrected thresholds do not consider the amount of fish sizes available to the birds or the amount of fish removed by the fishing industry

\begin{tabular}{|c|c|c|c|c|}
\hline \multirow[t]{2}{*}{ Method } & \multirow{2}{*}{$\begin{array}{c}\text { Estimated } \\
\text { biomass (t) }\end{array}$} & \multirow{2}{*}{$\begin{array}{c}95 \% \text { confidence } \\
\text { interval }(\mathrm{t})\end{array}$} & \multicolumn{2}{|c|}{ \% Maximum } \\
\hline & & & 1 yr max. $^{a}$ & Avg. $5 \mathrm{yr}^{\mathrm{b}}$ \\
\hline \multicolumn{5}{|l|}{ Cury et al. (2011) } \\
\hline Uncorrected & 217077 & $153734-359096$ & 12.4 & 18.0 \\
\hline \multicolumn{5}{|l|}{ Segmented regression } \\
\hline Uncorrected & 132300 & $45160-219400$ & 7.5 & 11.0 \\
\hline Corrected for size of fish & 97370 & $28700-166000$ & 5.6 & 8.1 \\
\hline Corrected for fishing + size of fish & 78840 & 49 090-108600 & 4.5 & 6.5 \\
\hline
\end{tabular}

tion estimates that they considered were impacted by commercial fisheries. In the GSL, Atlantic mackerel were highly abundant (reaching over 1.5 million $\mathrm{t}$ ) in the 1980s; their stock remained high until the mid 1990s and then dropped suddenly, apparently related to a climate-driven regime shift affecting the food chain (Plourde et al. 2015). Indeed, during this period, fishing landings could not explain the large decrease in mackerel abundance because landings were only a tiny fraction of the SSB (1 to $2 \%$ ).

However, the relative influence of fishing increased as the SSB decreased over time, reaching $13 \%$ in 2003 and peaking at $73 \%$ in 2010 , leaving only about $7000 \mathrm{t}$ of mackerel for other predators, which is less than the food requirements of gannets alone (7700 t in 2010). Obviously, such results stem

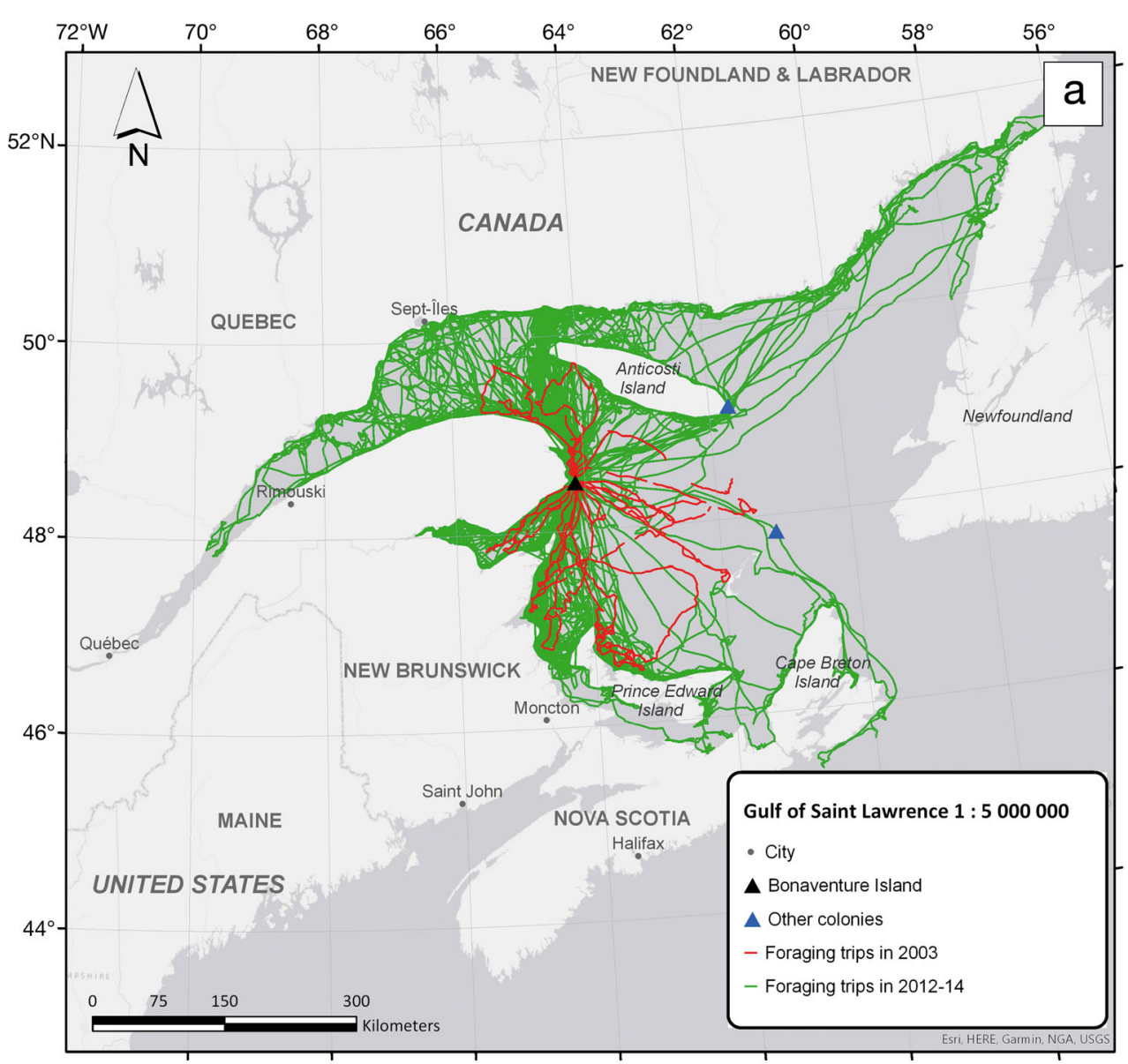

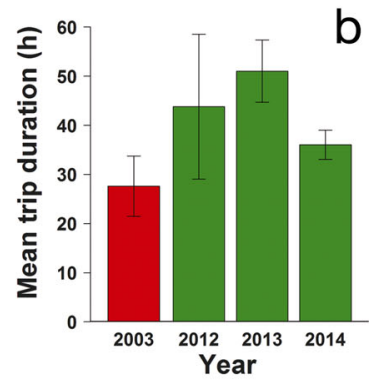

Fig. 4. (a) Foraging distribution of northern gannets breeding at Bonaventure Island during the chick-rearing periods of 2012 to 2014 (green lines; 273 trips by 63 birds) compared to 2003 (red lines, 20 trips by 14 birds) (data from Garthe et al. 2007). (b) Time spent at sea by gannets during foraging trips, derived from GPS recordings during 2012 to 2014 compared to 2003 
from the limitations of our data set. In fact, the biomass estimated by the mackerel egg survey represents only a minimum amount of fish because it measures only the mature fraction of the stock. Moreover, one must consider the possibility that the proportion of mackerel spawning outside the southern GSL changes from year to year. Another weakness of our data set is the absence of diet data for several years of the time series, and that we used $54 \%$ as the relative importance of mackerel as constant in our bio-energetic model. When considering the historical record of Taylor \& Nettleship (1974), the relative importance of mackerel varies between years (see 'Results') and it is possible that the 2010 and 2012 seasons were associated with a relative importance of mackerel lower than $54 \%$. This is particularly plausible as these 2 years were associated with the lowest mackerel SSB recorded in the time series.

Nevertheless, despite these caveats we believe our estimates of the mackerel biomass removed by gannets and the fishing industry to be a major strength of our approach. It shows that the poor breeding success of gannets was associated with an acute shortage of their preferred prey (see below), for which they were potentially competing with other predators. However, the relative importance of mackerel in the diet of grey seals Halichoerus grypus is minute in the southern GSL (0.7\% mass; Hammill et al. 2007, Hammill 2011), and Atlantic bluefin tuna Thunnus thynnus visits the southeastern part of the GSL only in small numbers (Wilson et al. 2011). Thus, we concluded that fisheries impact was negligible at the beginning of the time series, but its relative effect increased considerably with the decrease in mackerel stock, thereby indicating a potential competition with gannets.

Not all prey items are equally available to a predator. Because gannets rarely dive deeper than $10 \mathrm{~m}$, we expect food found deeper in the water column to be unavailable to such plunge-diving predators. This is particularly important under the observed rise in sea-surface temperature (SST) in many oceans across the world, as increases in SST might influence the depth distribution of most fish species. Unfortunately, we do not have data about the depth distribution of mackerel in the GSL, and therefore we cannot correct the SSB in relation to that factor. However, another aspect that might influence the fraction of biomass available to gannets is prey size. Camphuysen (2011) measured experimentally that northern gannets prefer fish prey smaller than $35 \mathrm{~cm}$, probably because larger prey cannot be swallowed whole. Therefore, using information about the size of fish collected from mackerel landings, we removed all mackerel larger than $35 \mathrm{~cm}$ in our estimate of available biomass. We found that doing so decreased our CT of food abundance from 132300 to $97370 \mathrm{t}$. The threshold was further reduced to $78840 \mathrm{t}$ when both the amount of fish taken by the industry and those too large to be taken by gannets were considered in our estimate. Clearly, any conservation-oriented estimates of food abundance in the context of ecosystem based management should take these 2 aspects into consideration.

\section{Theoretical considerations}

Our uncorrected CT (132 300 t) of MPA (1 $754052 \mathrm{t}$ ) represents $7.5 \%$, which is much less than the average of $34 \%$ (CI $=31-39 \%$ ) given by Cury et al. (2011). However, these authors used a different and nonlinear model to estimate their threshold. Using their method (Cury et al. 2011, their supplementary material), we found that breeding success would start to decrease at $12 \%$ (see Fig. S1 in the Supplement at www.int-res.com/articles/suppl/m587p235_supp.pdf), which is still lower than $34 \%$ and outside the confidence intervals computed by these authors. Although it may seem trivial to obtain different results when using a different modelling tool, choosing the right tool is not. We used a linear model in this study (Fig. 3a) because it was considered a more parsimonious approach: linear models are simpler, and if we can explain the same variability compared to a nonlinear model, it could be more parsimonious. After testing various approaches, Cury et al. (2011, their Table S2) found the best fit for their data with asymptotic models (although the difference from linear models was small). However, there are several examples in the literature of both linear and non-linear relationships of food abundance and breeding success of birds (see Newton 1998 for a comprehensive review), and discriminating which model should apply on a theoretical basis is, at best, difficult. This is because the breeding success of birds may vary in relation to many other factors such as predation, parasite loads, etc., which are unrelated to food supplies (Cairns 1992). In addition, behavioural flexibility might differ between species, as some birds may use behavioural compensation when food is scarce (e.g. work harder) in order to maintain or buffer conditions of food shortage. For instance, gannets from Bonaventure Island increased their foraging ranges and time spent at sea considerably under conditions of low food abundance (Fig. 4). Therefore, we can only conclude that further 
research should be conducted in this field in order to identify the mechanisms by which one or another model may best apply to the data at hand.

Apart from the form of the numerical (demographic) response, there must be other reasons that explain the large discrepancy between the 2 studies (i.e. CT of 35 vs. $12 \%$ ). We question here how the preference for a specific prey would influence the level of the CT of food biomass. Not all prey are equal in terms of foraging profitability (defined as the gain of energy per unit of time) since they might differ in terms of size, energy density, digestibility and depth distribution. Therefore, at a similar level of prey abundance, we expect foraging profitability to differ among prey items. Four reasons led us to believe that the Atlantic mackerel should be the preferred prey of northern gannets in the GSL: this species is (1) large and (2) of very high energy density among pelagic fishes and (3) found mostly in shallow waters. The fact that (4) mackerel dominated the diet (>70\%) during some years (1974 and 2005) also supports our working assumption. Thus, for a similar level of food biomass, the energy return associated with preferred prey like mackerel should sustain a higher number of predators than alternative prey such as capelin or sand eel. In other words, each prey item would be associated with its own numerical response, and alternative prey would be associated with a lower CT of food abundance. This reasoning is embedded in both the diet model and the ideal free distribution of foraging theory (Stephens et al. 2007), where only the abundance of the preferred prey will dictate whether prey switching does or does not occur. The implication here is that a CT of food abundance would be altered when a predator feeds on alternative prey. Supporting evidence of such an interpretation was given by Furness (2007), who could not detect any relationship between the breeding success of northern gannets on Foula in Shetland and the abundance of sand eels, which greatly varied over a time series of $30 \mathrm{yr}$. Martin (1989) made a similar observation on a nearby colony (Hermaness) where, despite large decreases of sand eels in the diet of gannets (associated with a decrease in abundance of this prey), their breeding success did not decrease. On the contrary, breeding success apparently increased together with gannet populations when sand eels were replaced in the environment by herring and mackerel. Thus, we suggest that further empirical determinations of the $\mathrm{CT}$ of food biomass should investigate if predators are (or are not) feeding on preferred prey, and test if the CT approach also applies to alternative prey.
Another and final consideration is the possibility that density-dependent effects will influence the computed CT of food biomass. In theory, larger populations of predators may influence the CT of food abundance at which breeding success starts to decrease. This aspect was not discussed by Cury et al. (2011) even though the investigated population sizes varied, sometimes by an order of magnitude or more. An obvious characteristic of breeding birds is that reproductive individuals are travelling back and forth between feeding sites and the nest, and for these reasons are considered to be 'central-place foragers'. In such a situation, individuals in growing colonies of seabirds could suffer from an increase in intra-specific competition for food through time, which ultimately would decrease breeding success. This hypothesis has been labelled Ashmole's Halo (see Gaston et al. 2007 for a review). One possible prediction, then, is that individuals from larger colonies, suffering from a higher level of local food depletion, should cover larger distances to feed and hence have larger foraging ranges compared to smallcolony individuals. Spatially linked evidence supporting such a prediction was provided for northern gannets in a comparison of foraging ranges of British colonies of various sizes (Lewis et al. 2001). The critical assumption underlying such a prediction is that large-colony individuals suffer from a higher level of depletion than small-colony individuals, although such an assumption ignores the possibility that larger colonies are a priori located exactly where food supplies are the largest. For instances, the 2 largest gannet colonies of the GSL are located on each side of the mackerel spawning grounds while a third, tiny colony is located far away from this source of food. More importantly, all British colonies were still growing at the beginning of 2000 (Wanless et al. 2005), suggesting that the size of the colony had no negative effect on reproductive success in the colonies studied by Lewis et al. (2001).

However, at this stage in our study we may wonder how time-linked variation in population size may influence the computation of CT and our conclusions. For example, our recordings of foraging ranges derived from GPS recordings (Fig. 4), and data of population size and breeding success are consistent with Ashmoles' Halo hypothesis. However, we believe that the population size of gannets did not play an important role in our study. For instance, by correcting the abundance of mackerel for the predators' population size, we get a similar curve to the uncorrected abundance versus breeding success curve (Fig. 3c). This is readily explained by the fact that most gannet 
population growth took place between 1976 and 2004 (Fig. 3b), a period when breeding success varied little ( $73 \%$ on average); the population stabilized afterwards (2004 to 2014) at 154 000 individuals on average $(\mathrm{CV}=4 \%)$, together with a decrease in breeding success starting in 2008. For the same periods, there was a sizable food biomass between 1976 and 2004 at about $700000 \mathrm{t}(\mathrm{CV}=66 \%)$ on average, and about $60000 \mathrm{t}(\mathrm{CV}=49 \%)$ between 2004 and 2014. Thus, most of the variation in breeding success was associated with a large decrease and high variability in food abundance at the same time the population size was stable. One reason that could possibly explain the absence of density dependence in our system is that gannets in the GSL were decimated by travellers and fishermen in the 19th century (Gosselin 2015); the observed increase in the size of the population is a recovery response. Although we could not find any evidence for a density dependent process in our study, we believe that this warrants further research in the future. Furthermore, because mackerel were abundant at the beginning of the time series and predation by gannets removed only a tiny/negligible portion of the fish biomass, stock failure could not be explained by gannet predation.

We conclude that gannet breeding failure is directly linked to food depletion in our system, even though the CT of MPA observed in our study does not match a similar threshold proposed from a previous metaanalysis. We believe that analyses such as this are certainly persuasive in demonstrating a common pattern and should be highly valuable for ecosystem based management practice and advice. However, we suggest that further research should include factors that may affect feeding profitability, diet and prey availability for seabirds together with the effect of fisheries in order to improve the veracity and usefulness of ecological predictions.

Acknowledgements. Fieldwork was conducted in accordance with guidelines of the Canadian Council on Animal Care, with review and approval by the Université du Québec à Rimouski Animal Care Committee (permit number CPA-65-16-177), Canadian Wildlife Service (CWS) of Environment Canada (Québec region) (permit numbers SC25, RE-27, 10704 M, $10704 \mathrm{~T}$ ) and Société des établissements de plein air du Québec (permit numbers PNIBRP2012-001, PNIBRP-2013-001, PNIBRP-2014-001). This study was funded through the Canadian Natural Sciences and Engineering Research Council (NSERC) discovery and equipment grants to M.G. and Fonds de recherche du Québec - Nature et Technologies (FRQNT) Research program for college researchers to D.P. (FRQNT-146290). We acknowledge the contribution of long-term monitoring programs of gannets and other seabirds under the auspice of CWS of Environment Canada (Québec region) and the long- term monitoring programs of mackerel abundance data, fishing statistics, and commercial samples from the Department of Fisheries and Oceans (DFO) Canada (Québec region). Thanks for the extensive commitment of sampling, laboratory and analytical personnel involved at Université du Québec à Rimouski (Yannick Seyer, Laurie Maynard, Sarah Wing, Isabeau Pratte, Mélanie Laflèche, Catherine Ayotte), Cégep de Rimouski (Gabrielle Bouchard, AnneCharlotte Lebel, Daisy Turcotte, Laura Turcotte), CWS and DFO during all those years. Thanks to Parc national de l'îleBonaventure-et-du-Rocher-Percé and its staff for transportation and supportive collaboration. Final thanks to Kyle Elliott and many anonymous reviewers for helpful comments.

\section{LITERATURE CITED}

Bertrand S, Joo R, Smet CA, Tremblay Y, Barbraud C, Weimerskirch $H$ (2012) Local depletion by a fishery can affect seabird foraging. J Appl Ecol 49:1168-1177

Birt-Friesen VL, Montevecchi WA, Cairns DK, Macko SA (1989) Activity-specific metabolic rate of free-living northern gannets and other seabirds. Ecology 70: 357-367

Cairns DK (1987) Seabirds as indicators of marine food supplies. Biol Oceanogr 5:261-271

Cairns DK (1992) Bridging the gap between ornithology and fisheries science: use of seabird data in stock assessment models. Condor 94:811-824

Camphuysen KS (2011) Northern gannets in the North Sea: foraging distribution and feeding techniques around the Bass Rock. Br Birds 104:60-76

Cooper J (1978) Energetic requirements for growth and maintenance of the cape gannet (Aves, Sulidae). Afr Zool 13:305-317

Cury PM, Boyd IL, Bonhommeau S, Anker-Nilssen T and others (2011) Global seabird responses to forage fish depletion - one-third for the birds. Science 334:1703-1706

Danckwerts DK, McQuaid CD, Jaeger A, McGregor GK, Dwight R, Le Corre M, Jaquemet S (2014) Biomass consumption by breeding seabirds in the western Indian Ocean: indirect interactions with fisheries and implications for management. ICES J Mar Sci 71:2589-2598

Frederiksen M, Mavor RA, Wanless S (2007) Seabirds as environmental indicators: the advantages of combining data sets. Mar Ecol Prog Ser 352:205-211

Furness RW (2007) Responses of seabirds to depletion of food fish stock. J Ornithol 148(Suppl 2):247-252

*Garthe S, Montevecchi WA, Chapdelaine G, Rail JF, Hedd A (2007) Contrasting foraging tactics by northern gannets (Sula bassana) breeding in different oceanographic domains with different prey fields. Mar Biol 151:687-694

Garthe S, Guse N, Montevecchi WA, Rail JF, Grégoire F (2014) The daily catch: flight altitude and diving behavior of northern gannets feeding on Atlantic mackerel. J Sea Res 85:456-462

Gaston AJ, Ydenberg RC, Smith GEJ (2007) Ashmole's halo and population regulation in seabirds. Mar Ornithol 35: 119-126

Gosselin M (2015) L'île aux trésors: d'Audubon à James Bond. QuébecOiseaux 26:12-18

Grégoire F, Faucher S (2006) Distribution and abundance of the Atlantic mackerel (Scomber scombrus L.) eggs for the ichthyoplankton surveys conducted in the southern Gulf of St. Lawrence between 1976 to 1979. DFO Can Sci Advis Sec Res Doc 2006/099

Grégoire F, Beaulieu JL, Gendron MH, LeBlanc D (2013a) 
Results of the Atlantic mackerel (Scomber scombrus L.) egg survey conducted on the Scotian Shelf and Newfoundland's south coast in 2009. DFO Can Sci Advis Sec Res Doc 2012/127

Grégoire F, Barry W, Barry JJ, Barry J, Beaulieu JL, Gendron MH (2013b) West coast of Newfoundland capelin (Mallotus villosus M.) and Atlantic herring (Clupea harengus harengus L.) larval survey, Part 10: Abundance estimates and marine community analyses of the data collected in partnership with the industry (Barry Group) in July 2009 and comparison with previous surveys. Can Tech Rep Fish Aquat Sci 3062

Grégoire F, Girard L, Boudreau M (2014) Résultats des relevés du programme de monitorage zonal Atlantique (PMZA)-maquereau bleu (Scomber scombrus L.) réalisés dans le sud du Golfe Saint-Laurent en 2012 et 2013. Secr Can de Consult Sci du MPO. Doc de rech 2014/075

Hamer KC, Humphreys EM, Garthe S, Hennicke J and others (2007) Annual variation in diets, feeding locations and foraging behaviour of gannets in the North Sea: flexibility, consistency and constraint. Mar Ecol Prog Ser 338: 295-305

Hammill MO (2011) Feeding of grey seals in southern Gulf of St. Lawrence. DFO Can Sci Advis Sec Res Doc 2010/130

Hammill MO, Stenson GB, Proust F, Carter P, McKinnon D (2007) Feeding by grey seals in the Gulf of St. Lawrence and around Newfoundland. NAMMCO Sci Publ 6: 135-152

Hunsicker ME, Ciannelli L, Bailey KM, Buckel JA and others (2011) Functional responses and scaling in predator-prey interactions of marine fishes: contemporary issues and emerging concepts. Ecol Lett 14:1288-1299

Lewis S, Sherrat TN, Hamer KC, Wanless S (2001) Evidence of intra-specific competition for food in a pelagic seabird. Nature 412:816-819

Martin AR (1989) The diet of Atlantic puffin Fratercula artica and northern gannet Sula bassana chicks at a Shetland colony during a period of changing prey availability. Bird Study 36:170-180

Montevecchi WA, Ricklefs RE, Kirkham IR, Gabaldon D (1984) Growth energetics of nestling northern gannets (Sula bassanus). Auk 101:334-341

Muggeo VMR (2003) Estimating regression models with unknown break-points. Stat Med 22:3055-3071

Muggeo VMR (2008) segmented: an R package to fit regression models with broken-line relationships. R News 8: 20-25

Newton I (1998) Population limitation in birds. Academic Press, New York, NY

* Paleczny M, Hammill E, Karpouzi V, Pauly D (2015) Population trend of the world's monitored seabirds, 1950-2010. PLOS ONE 10:e0129342

Peck MA, Neuenfeldt S, Essington VM, Trenkel A and others (2014) Forage fish interactions: a symposium on 'Creating the tools for ecosystem-based management of marine resources'. ICES J Mar Sci 71:1-4

Piatt JF, Harding AMA, Shultz M, Speckman SG, van Pelt TI, Drew GS, Kettle AB (2007) Seabirds as indicators of marine food supplies: Cairns revisited. Mar Ecol Prog Ser 352:221-234

Editorial responsibility: Rory Wilson,

Swansea, UK
Pichegru L, Grémillet D, Crawford JM, Ryan PJ (2010) Marine no-take zone rapidly benefits endangered penguin. Biol Lett 6:498-501

* Plourde S, Grégoire F, Lehoux C, Galbraith PS, Castonguay M, Ringuette M (2015) Effect of environmental variability on body condition and recruitment success of Atlantic mackerel (Scomber scombrus) in the Gulf of St. Lawrence. Fish Oceanogr 24:347-363

Poulin JM (1968) Reproduction du Fou de Bassan (Sula bassana), île Bonaventure, Québec. MSc thesis, Université Laval, Québec

R Core Team (2015) R: a language and environment for statistical computing. R Foundation for Statistical Computing, Vienna. www.r-project.org

Rail JF, Champoux L, Lavoie RA, Chapdelaine G (2013) Suivi de la population et de la contamination du Fou de Bassan au Québec, 1966-2009. Série de rapports techniques no 528. Environnement Canada. Service canadien de la faune, région du Québec, Environnement Canada, Québec

Kobinson WML, Butterworth DS, Plaganyi EE (2015) Quantifying the projected impact of the South African sardine fishery on the Robben Island penguin colony. ICES J Mar Sci 72:1822-1833

Saville A (ed) (1977) Survey method of appraising fishery resources. FAO Fish Tech Pap 171:1-76

Sette OE (1943) Biology of the Atlantic mackerel (Scomber scombrus L.) of North America. Part 1: Early life history, including the growth, drift, and mortality of the egg and larval populations. Fish Bull 38:149-237

* Shelton AO, Samhouri JF, Stier AC, Levin PS (2014) Assessing trade-offs to inform ecosystem-based fisheries management of forage fish. Sci Rep 4:7110

Spitz J, Jouma J (2013) Variability in energy density of forage fishes from the Bay of Biscay (north-east Atlantic Ocean): reliability of functional grouping based on prey quality. J Fish Biol 82:2147-2152

Stephens DW, Brown JS, Ydenberg RC (eds) (2007). Foraging: behavior and ecology. University of Chicago Press, Chicago, IL

Taylor PS, Nettleship DN (1974) The seabirds of Bonaventure Island, Percé Rock and area, Québec, in summer 1974. Environment Canada Report No. 29, Canadian Wildlife Service, Ottawa

*Velarde E, Ezcurra E, Anderson DW (2013) Seabird diets provide early warning of sardine fishery declines in the Gulf of California. Sci Rep 3:1332

Wanless S, Murray S, Harris MP (2005) The status of northern gannet in Britain \& Ireland in 2003/04. Br Birds 98: 280-294

Wilson RP, Pütz K, Peters G, Culik BM, Scolaro JA, Charrassin JB, Ropert-Coudert Y (1997) Long-term attachment of transmitting and recording devices to penguins and other seabirds. Wildl Soc Bull 25:101-106

Wilson SG, Lawson GL, Stokesbury MJW, Spares A, Boustany AM, Neilson JD, Block BA (2011) Movements of Atlantic bluefin tuna from the Gulf of St. Lawrence to their spawning grounds. Col Vol Sci Pap ICCAT 66:1247-1256

Wood SN (2001) Minimizing model fitting objectives that contain spurious local minima by bootstrap restarting. Biometrics 57:240-244

Submitted: November 7, 2016; Accepted: December 4, 2017 Proofs received from author(s): January 21, 2018 